\title{
Impact of Fatty Acids on Obesity-Associated Diseases and Radical Weight Reduction
}

\author{
Małgorzata Wrzosek ${ }^{1,2}\left(\right.$ D $\cdot Z_{\text {Zuzanna Zawadzka }}{ }^{2}$ Ada Sawicka $^{3} \cdot$ Barbara Bobrowska-Korczak $^{4} \cdot$ Agnieszka Białek $^{5}$
}

Received: 14 September 2021 / Revised: 26 October 2021 / Accepted: 9 November 2021 / Published online: 23 November 2021

(c) The Author(s) 2021

\begin{abstract}
Purpose Fatty acids (FA), particularly polyunsaturated (PUFA) ones, are involved in the regulation of glycemic control, lipid metabolism, and inflammation. The aim of the study was to assess patient FA profile in relation to obesity, lipid and carbohydrate metabolism disturbances, and weight loss.

Materials and Methods The studied group consisted of 51 patients with extreme obesity, 23 of whom achieved radical weight reduction within 1 year after a laparoscopic sleeve gastrectomy (LSG). FA levels were determined using gas chromatography with flame ionization detection.

Results Patients with extreme obesity and higher serum PUFA content have lower serum levels of SFA and MUFA (especially myristic, palmitic, lignoceric acids and palmitoleic, oleic acids), as well as lower triglyceride and higher HDL-cholesterol concentrations and it was not influenced by CEPT Taq1B variant. At baseline, the fatty acid profile of patients with type II diabetes differ from patients with dyslipidemia. In patients who had lost weight, significantly lower levels of selected saturated FA and major trans-fatty acid, elaidic, were found. Moreover, the proportion of PUFA was increased.

Conclusion In extreme obesity, higher PUFA exert their favorable effects on serum lipids. Significant weight reduction after the bariatric surgery is associated with beneficial changes in the fatty acid profile.
\end{abstract}

Keywords Fatty acids $\cdot$ Bariatric surgery $\cdot$ Obesity $\cdot$ Metabolic disturbances

\section{Key Points}

- Higher serum PUFA content may be beneficial in bariatric surgery candidates.

- Serum fatty acid composition in patients with obesity differs in the presence of disturbances in glucose or lipid metabolism.

- After the bariatric surgery, the proportion of PUFA was increased and SFA decreased.

Małgorzata Wrzosek

malgorzata.wrzosek@wum.edu.pl

Zuzanna Zawadzka

zuzannazawadzka@yahoo.pl

Ada Sawicka

asaw73@o2.pl

Barbara Bobrowska-Korczak

bbobrowska@wum.edu.pl

Agnieszka Białek

a.bialek@ighz.pl

1 Department of Biochemistry and Pharmacogenomics, Faculty of Pharmacy, Medical University of Warsaw, 1 Banacha Street, 02-097 Warsaw, Poland

\section{Introduction}

According to the World Health Organization, the number of people with obesity throughout the world has almost tripled since 1975 [1]. Obesity was once considered a problem of rich and intensively developing countries, but it is now thought to affect people with low and medium socioeconomic status [2]. In individuals with obesity, the amount of energy supplied is much higher than the

2 Centre for Preclinical Research, Medical University of Warsaw, 1 Banacha Street, 02-097 Warsaw, Poland

3 Department of Family Medicine, Internal Medicine and Metabolic Bone Diseases, Center of Postgraduate Medical Education, 00-416, Warsaw, Poland

4 Department of Bromatology, Faculty of Pharmacy, Medical University of Warsaw, 1 Banacha St., 02-097 Warsaw, Poland

5 Institute of Genetics and Animal Biotechnology PAS, Postepu 36A, Jastrzębiec, 05-552 Magdalenka, Poland 
body's need, which results in excessive fat accumulation due to hypertrophy and/or adipocyte hyperplasia [3]. An energy imbalance results from taking in more calories than is required for body health and function. Every year, the percentage of overweight people increases due to the popularity of consuming foods high in fat and carbohydrates. Undoubtedly, body weight is also significantly influenced by eating habits, e.g., overeating, too long or too short breaks between meals, and eating to relieve negative emotions or anxiety [4]. In addition, people who have limited physical activity tend to gain weight. Their volume of lipid droplets in skeletal muscle is increased. Lower rates of triglyceride turnover, diminished oxidative enzyme activity, and lipid oxidation are also observed. These mechanisms lead to adipose tissue retention $[5,6]$. The energy contained in dietary fat comes mainly from saturated (SFA), monounsaturated (MUFA), and polyunsaturated (PUFA) fatty acids [7]. The most common SFA are palmitic and stearic acid, which are usually consumed in the diet in excessive amounts [8]. A recommended intake for these acids has not yet been established, nor has an upper safe dietary level. SFA are considered to adversely affect human health, because any increase in their content carries the risk of coronary heart disease or an increased concentration of low-density lipoprotein (LDL) cholesterol $[9,10]$. Fatty acids are stored in lipid droplets within adipocytes in the form of triglycerides. Excess fatty acid accumulation leads to an increase in mature adipocyte size [11]. Hypertrophic adipocytes tend to be insulin resistant. This results in greater lipolysis with less lipogenesis. Thus, increased fatty acid flux away from adipose tissue represents a key feature in the pathophysiology of the metabolic complications in obese individuals, such as poor glycemic control, dyslipidemia, and inflammation. MUFAs coexist with SFA in foods, especially in animal products. The most important food sources of MUFA are olive oil, animal fats (oleic acid, myristoleic, and palmitoleic acids) and rapeseed oil (erucic acid). PUFA constitute an important group of human nutrients. Unlike SFA, not all PUFA can be synthesized by human and animal tissues. This is due to a lack of special enzyme systems $\left(\Delta^{12}\right.$-desaturase and $\Delta^{15}$-desaturase) which would insert unsaturated bonds in positions 3 and 6 of the carbon chain. In animal tissues, it is only possible to remodel such chains and produce other polyunsaturated acid chains from them. Therefore, linoleic acid (LA) and $\alpha$-linolenic acid (ALA) belong to the so-called EFAs (essential unsaturated fatty acids) and they must be derived from dietary sources $[12,13]$. Unsaturated fatty acids are irreplaceable in young organisms for proper growth and development processes and contribute to the maintenance of good health throughout life. They have a role in building cellular membranes throughout the body and stimulate multiple signaling events in various tissues, mainly via eicosanoids derived from them and via direct effects on gene expression [14]. Moreover, studies have shown anti-inflammatory properties for long-chain $n-3$ polyunsaturated fatty acids (n-3 PUFA) $[15,16]$, which directly modulate the activity of the key pro-inflammatory transcription factor NF- $\kappa \mathrm{B}$ [17]. EPA and DHA have established cardiovascular benefits [18-20]. Fatty acids in serum cholesteryl esters regulate cholesterol homeostasis by participating in the transport and oxidation of cholesterol [21]. For example, n-3 PUFA reduce endogenous triglyceride synthesis and enhance the blood clearance of triglyceride-rich particles, stimulate the inhibition of lipogenesis, promote fat oxidation and reduce fat deposition, thereby counteracting obesity and dyslipidemia [22, 23]. Omega-3 fatty acids may also reduce insulin resistance, which is of importance in diabetes prevention [24, 25]. Thus, the aim of the study was to assess fatty acid profile in relation to obesity, obesity-associated diseases, and weight reduction. We considered that an investigation in obese individuals might be important in determining an individual's risk of developing lipid and carbohydrate disturbances and might also provide useful information about the role of selected fatty acids in metabolic alterations, inflammation, and maintaining weight loss. We verified also the influence of cholesteryl ester transfer protein (CETP) gene variant (Taq1B) on fatty acid contents. It is speculated that variations in the CETP gene may modulate the effects of dietary components on metabolic traits and individuals homozygous for the $\mathrm{B} 2$ genotype have higher HDL-C concentrations and reduced risk of the metabolic syndrome than those with the B1 homozygous genotype [26, 27]. In the present study, chemometric approach has been proposed as an objective method for the evaluation and data interpretation of large data sets of fatty acid share in serum samples of three groups of patients (individuals with obesity, with obesity and co-existing dyslipidemia, and with obesity and co-existing diabetes).

\section{Materials and Methods}

\section{Study Group and Study Design}

Unrelated subjects with morbid obesity $(\mathrm{BMI}=46.2 \pm 4.44$; range 40.0-56.0), over 35 years of age, were consecutively recruited from patients prior to bariatric surgery. A detailed history of obesity and a full physical examination was obtained for each patient. Obesity was classified according to the World Health Organization criteria [28]. In all subjects, anthropometric measurements (body weight and height) were taken and body mass index (BMI) 
was calculated as the ratio of weight (kilograms) to the square of height (meters). The data on DXA-derived measures of total body fat (fat mass expressed as \% fat mass and $\mathrm{kg}$ ) was available for the whole group of participants. Within the 12 months following a laparoscopic sleeve gastrectomy (LSG), only those patients with marked weight loss were enrolled in prospective, observational study. The percent changes of BMI values were determined by the Eq. $100 \times(\mathrm{BMI}$ at baseline $-\mathrm{BMI}$ at follow-up $) / \mathrm{BMI}$ at baseline. The study was carried out in accordance with the principles of the Declaration of Helsinki. The whole study protocol was approved by the Institutional Bioethics Committees. Subjects' weight and height were measured, and body mass index (BMI) was calculated at pre-surgery and follow-up visits. Determination of dyslipidemia was based on a current or previous medical diagnosis according to the National Cholesterol Education Program-Adult Treatment Panel III [29]. Patients were classified as diabetics based on the review of medical records (an average fasting plasma glucose concentration $\geq 126 \mathrm{mg} / \mathrm{dl}$ on two occasions [30], previous diagnosis of diabetes by a physician, and current use of diabetes medications) and confirmed by current medical examination. Only patients whose type II diabetes was diagnosed after the age of 30 were included in the analyses. Criteria for exclusion from the study were as follows: acute endocrine dysfunction, pregnancy, previous bariatric surgery, and alcoholism. In addition, individuals with prediabetes were excluded from the study [30]. The primary outcome was the relation of FA to obesity-associated disturbances of glucose and lipid metabolisms and to changes in serum FA after significant weight reduction.

\section{Biochemical Analysis}

Blood samples were drawn in the morning after $12-\mathrm{h}$ overnight fasting at the time of surgery (pre-surgery) and during the follow-up visit. Biochemical parameters measured included total cholesterol (TC), HDL-cholesterol (HDL-C), LDL-cholesterol (LDL-C), triglycerides (TG), fasting blood glucose (FBG), HbA1c (\%), folic acid, vitamin B12, C-reactive protein (CRP), aspartate aminotransferase (ASP), alanine aminotransferase (ALT), insulin, and IL-6. Laboratory analyses were performed by routine laboratory methods. Serum levels of interleukin 6 (IL-6) was determined by the ELISA method using the Diaclone Human IL-6 High Sensitivity ELISA kit (950.035.192). Serum levels of insulin were determined by the ELISA method using the DRG® Insulin ELISA (EIA-2935) kits. Insulin resistance was assessed using the homeostasis model assessment [HOMA-IR index $=$ (fasting glucose in $\mathrm{mmol} / \mathrm{L}$ * fasting insulin in $\mu \mathrm{IU} / \mathrm{mL}) / 22.5$ ] [31].

\section{Fatty Acid Analysis in Serum}

Fatty acid analyses were performed with gas chromatography (GC) using a gas chromatograph (GC-17A Shimadzu, Japan) equipped with a capillary column (BPX 70; $60 \mathrm{~m} \times 0.25 \mathrm{~mm}$ i.d., film thickness $0.20 \mu \mathrm{m}$, SGE, Ringwood, Australia) and a flame-ionization detection (FID). Helium (Multax) was the carrier gas. The initial oven temperature was $140{ }^{\circ} \mathrm{C}$ for $1 \mathrm{~min}$ after that increased by $20^{\circ} \mathrm{C} / \mathrm{min}$ to $200^{\circ} \mathrm{C}$ and held for $20 \mathrm{~min}$ and increased by $5{ }^{\circ} \mathrm{C} / \mathrm{min}$ to $220{ }^{\circ} \mathrm{C}$ held for $25 \mathrm{~min}$. The injector was heated to $250^{\circ} \mathrm{C}$, and the detector to $270{ }^{\circ} \mathrm{C}$. Fatty acid methyl esters (FAME) standards (Supelco 37 Component FAME Mix, Sigma, St. Louis, MO, USA), CLA FAME reference standard (Nu-Chek-Prep, INC., USA), PA methyl ester reference standard (methyl punicate, Matreya LLC, USA) were used to identify the fatty acids present in samples. The serums were thawed only once, and samples of $100 \mu \mathrm{l}$ were trans-esterificated according to the procedure of Bondia-Pons et al. [32]. with minor modifications. Without prior lipid extraction, the serum samples were hydrolyzed by heating with $2.5 \mathrm{ml}$ of sodium methoxide in methanol $(0.5 \mathrm{~mol} / \mathrm{l})$ at $80^{\circ} \mathrm{C}$ for $10 \mathrm{~min}$. FA were converted into methyl esters by heating with $2.5 \mathrm{ml}$ of $14 \%$ boron trifluoride-methanol reagent at $80{ }^{\circ} \mathrm{C}$ for $3 \mathrm{~min}$. FAME were isolated with hexane $(2 \times 0.5 \mathrm{ml})$ after adding $1.0 \mathrm{ml}$ of saturated sodium chloride solution. Organic extracts were dried over anhydrous sodium sulfate and evaporated to dryness under a stream of nitrogen. FAME were diluted in $20 \mu \mathrm{l}$ of hexane and stored at $-20{ }^{\circ} \mathrm{C}$ until being analyzed. Results were expressed as percentage of total fatty acids present in serum. The fatty acids determined in patients are presented in Table 2.

\section{CETP Genotyping}

DNA was extracted from the leukocytes of the whole blood leucocytes with a DNA extraction kit (A\&A Biotechnology, Poland). The Taq1B genotype (rs708272) of the cholesteryl ester transfer protein (CETP) gene was determined by a polymerase chain reaction using primers as described by Mohrschlad et al. [33]. DNA was amplified in a 25- $\mu 1$ reaction mixture containing $25 \mathrm{pmol}$ of each primer, $100 \mathrm{ng}$ genomic DNA, $0.2 \mathrm{mmol} / \mathrm{l}$ of each dNTP, $1.5 \mathrm{mM} \mathrm{MgCl} 2$, and 0.2 U Taq polymerase (BioTaq, Bioline Reagents, UK). The amplification was performed at $94{ }^{\circ} \mathrm{C}$ for $4 \mathrm{~min}$, followed by 35 cycles at $94{ }^{\circ} \mathrm{C}$ for $30 \mathrm{~s}, 64^{\circ} \mathrm{C}$ for $30 \mathrm{~s}$, and $72{ }^{\circ} \mathrm{C}$ for $1.5 \mathrm{~min}$. A fragment of $505 \mathrm{bp}$ in intron 1 of the CETP gene was amplified by polymerase chain reaction (PCR). The PCR products were subjected to restriction enzyme analysis by digestion with Taq1 restriction endonucleases (Fermentase Canada) at $65^{\circ} \mathrm{C}$ for $1 \mathrm{~h}$. The fragments were separated by electrophoresis on a $2.5 \%$ agarose gel and stained with ethidium bromide. DNA fragments were 
visualized by UV illumination. The resulting fragments were $505 \mathrm{bp}$ and $90 \mathrm{bp}$ for the "B1' allele and $505 \mathrm{bp}$ for the uncut "B2" allele.

\section{Statistical Analysis}

Statistica 13.0 (StatSoft, Poland) was used to conduct a statistical analysis of the results. The normality assumptions were estimated with Shapiro-Wilk's test, and whenever the normality and variance homogeneity assumptions were fulfilled, one-way analysis of variance (ANOVA) with post hoc Tukey's test was used to determine the relationships between the 3 groups. If the assumptions of the analysis of variance were not met, the non-parametric Kruskal-Wallis test, which is a non-parametric equivalent of one-way ANOVA, with post hoc multiple comparison test was used. Pearson's $\chi^{2}$ tests were used to find a link between the CEPT Taq1B variant and PUFA level in obese subjects. Paired $t$-test was used to compare values at baseline with 12 months post-surgery values. Subjects were divided into quintiles of PUFA levels; Mann-Whitney rank tests and $t$-tests were used to assess differences between the groups. Spearman's coefficients were used to estimate potential correlations between CRP (C-reactive protein) and FFA contents and selected biochemical parameters. In order to better understand the data trends, fatty acid profiles were considered as chemical descriptors to study a possible discrimination of serum samples from patients with obesity, with obesity and dyslipidemia, and with obesity and type II diabetes. Prior to chemometric analyses, the original data were transformed into natural logarithms and then standardized. Similarity analysis was performed for variables differing significantly among those three groups of patients, and grouping of features and objects was carried out to prepare heat map. Moreover, in order to obtain appropriate classification rules for serum samples into obesity, obesity with dyslipidemia, and obesity with type II diabetes, a linear discriminant analysis (LDA) was performed. Relevant discriminant functions were calculated in a stepwise progressive method, with the adopted tolerance value $1-R^{2}=0.01$ to optimize LDA.

\section{Results}

Biochemical characteristics and anthropometric parameters of 51 participants with extreme obesity and prior bariatric surgery are presented in Table 1 . The mean BMI value of the subjects was $46.20 \pm 4.44 \mathrm{~kg} / \mathrm{m}^{2}$. The study group consisted of 37 women and 14 men with the mean age $44.8 \pm 6.6$ years. In our experiment, we analyzed 36 fatty acids, including 15 saturated fatty acids (SFA), 9 monounsaturated fatty acids (MUFA), and 12 polyunsaturated fatty acids (PUFA).
Participants were divided into quartiles of PUFA level (Table 1). It was shown that obese patients in the highest quartile of serum PUFA (\% PUFA $>32.84 \%$ ) had a significantly higher HDL-cholesterol levels $(p=0.01)$ and lower triglyceride concentration $(p=0.03)$, even though they had higher BMIs. Genotype B2B2 of CEPT Taq1B variant was not associated with higher PUFA level (Table 1).

The values are given as the means \pm standard deviations (SD). Bold data indicate significance difference. Abbreviations: b.p. blood pressure, $B M I$ body mass index, $H b A l c$ glycosylated hemoglobin, $H D L$-cholesterol high-density lipoprotein cholesterol, LDL-cholesterol low-density lipoprotein cholesterol, ESR erythrocyte sedimentation rate, $C R P$ C-reactive protein, AspAt aspartate aminotransferase, AlAt alanine aminotransferase.

Mann-Whitney rank tests and $t$-tests were used where appropriate. Pearson's $\chi 2$ tests were used to find a link between CEPT Taq1B B2B2 genotype and PUFA level. $P$ values were considered significant when $p<0.05$.

Palmitic (C16:0), oleic (C18:1 n-9), LA (linoleic, C18:2 $\mathrm{n}-6)$, and stearic (C18:0) acids were found to be the main fatty acids in the serum of the patients in the study (Table 2). In addition, patients with higher total percent PUFA had a significantly lower percentage of SFA, especially myristic (C14:0), palmitic (C16:0), lignoceric (C24:0), and lower percentages of MUFA, i.e., palmitoleic (C16:1 n-7) and oleic acids (cis-9 C18:1), whereas they had higher percentages of linoleic (LA, C18:2 n-6), arachidonic (C20:4 n-6), EPA (eicosapentaenoic), and DHA (docosahexaenoic) compared to patients with lower PUFA levels (\% PUFA $\leq$ Q3). We observed that total content of SFA and MUFA was lower in patients with a higher percent of PUFA and they had higher serum total $n-3$ as well as n-6 PUFA concentrations (Table 2).

The values are given as the means \pm standard deviations (SD). Bold data indicate significance difference. Mann-Whitney rank tests and $t$-tests were used where appropriate. $P$ values were considered significant when $p<0.05$.

We assessed the relationship between C-reactive protein (CRP) concentration and the fatty acid profile, and selected biochemical and anthropometric parameters in obese patients. Specifically, a positive correlation between CRP levels and the percentage of palmitic acid $(r=0.2965$; $p=0.035)$ and IL-6 $(r=0.2902 ; p=0.045)$ concentrations were found. However, only LA was an independent negative correlate of CRP $(r=-0.3450 ; p=0.013)$. The other parameters analyzed did not correlate statistically significantly with the CRP concentrations.

We grouped participants into three categories: the first consisted of patients with obesity without diabetes/dyslipidemia $(n=27)$, the second patients with obesity and type II diabetes (without dyslipidemia, $n=6$ ), and the third patients with obesity and dyslipidemia (without type II diabetes, 
$n=13)$. Patients with coexisting diabetes and dyslipidemia were excluded from the analyses. The heatmap visualization showed discrimination between analyzed groups of patients (Fig. 1).

Patients with extreme obesity and diabetes showed significantly higher percentages of the following fatty acids, C20:2 (eicosadienoic), C18:3 n-3 (ALA, $\alpha$-linolenic), DHA (docosahexaenoic), C20:0 (arachidic), C14:0 (myristic), and C20:3 n-3 (eicosatrienoic), which distinguished them from others (Fig. 1). Likewise, they had significantly higher average total percentages of $n-3$ acids $\left(\sum n-3 \%=2.47 \pm 0.65\right)$ than obese non-diabetic patients $\left(\sum \mathrm{n}-3 \%=1.71 \pm 0.63 \%\right.$; $\mathrm{p}=0.01)$ and lower $\mathrm{n}-6 / \mathrm{n}-3$ fatty acid ratio than obese nondiabetic patients $(10.66 \pm 2.75$ vs. $16.78 \pm 5.09 ; p<0.01)$. The above relationships could be due to the fact that patients with type II diabetes more often implemented healthy lifestyle and diet principles, which, apart from pharmacotherapy, are the basis for treatment of type II diabetes, and this may have had a positive effect on the fatty acid profile in these patients. However, patients with diabetes were characterized by statistically significantly higher body weight, and higher IL-6, fasting glucose, glycated hemoglobin levels than patients without type II diabetes (data not shown).
The characteristics of fatty acid profiles in relation to the occurrence of dyslipidemia were also analyzed. Similarity analysis revealed that serum samples of patients with dyslipidemia were characterized by a lower percentage of such saturated acids as C10:0 (capric), C12:0 (lauric), C20:0 (arachidic), and C23:0 (tricosylic) and a higher percentage of such MUFA as C16:1 (palmitoleic) (Fig. 1). Such relationships may have resulted from the hypolipidemic treatment implemented in these patients [34].

In the next step, LDA was used to obtain appropriate classification rules for patients from above-mentioned groups based on examination of fatty acid share in their serum samples. Relevant discriminant functions were calculated in a stepwise progressive method. Percentage share of 30 fatty acids, which were detected in all examined serum samples, were included in the model. In the performed analysis, 13 variables have been included in the final model, and 6 of them (eicosadienoic, myristic, arachidic, c9,t11 CLA, heneicosylic, and pentadecanoic acids) were significant in the model. All of them made a comparable contribution to overall discrimination. Applied canonical analysis allowed to distinguish 2 statistically significant discriminant functions (DF). DF1 is the most significant function, as it explains
Table 1 Basic characteristic of patients $(n=51)$ and differences between these parameters in patients with high $(>\mathrm{Q} 3)$ and low $(\leq \mathrm{Q} 3)$ PUFA levels

\begin{tabular}{|c|c|c|c|c|}
\hline Parameters & Total $(n=51)$ & $\begin{array}{l}\text { PUFA } \leq 32.84 \% \\
\text { (Q3) }(n=39)\end{array}$ & $\begin{array}{l}\text { PUFA }>32.84 \% \\
(\mathrm{Q} 3)(n=12)\end{array}$ & $p$ value \\
\hline $\begin{array}{l}\text { CEPT Taq1B variant (number of } \\
\text { B2B2 homozygous patients) }\end{array}$ & $\mathrm{n}=10(19.6 \%)$ & $\mathrm{n}=7(18 \%))$ & $\mathrm{n}=3(25 \%)$ & 0.37 \\
\hline Weight (kg) & $127.70 \pm 18.52$ & $125.39 \pm 17.81$ & $127.20 \pm 9.76$ & 0.27 \\
\hline $\operatorname{BMI}\left(\mathrm{kg} / \mathrm{m}^{2}\right)$ & $46.20 \pm 4.46$ & $45.28 \pm 4.28$ & $49.52 \pm 3.62$ & 0.04 \\
\hline Fat mass (kg) & $58.69 \pm 9.33$ & $57.9 \pm 9.82$ & $61.65 \pm 6.97$ & 0.35 \\
\hline Fat $(\%)$ & $47.40 \pm 4.36$ & $46.41 \pm 3.44$ & $48.39 \pm 2.87$ & 0.29 \\
\hline Lean mass (kg) & $62.66 \pm 9.25$ & $63.47 \pm 11.00$ & $62.88 \pm 9.254$ & 0.89 \\
\hline $\mathrm{HbA}_{1 \mathrm{c}}(\%)$ & $5.84 \pm 0.70$ & $5.89 \pm 0.72$ & $5.65 \pm 0.66$ & 0.30 \\
\hline Fasting glucose (mg/dl) & $97.20 \pm 19.14$ & $98.92 \pm 20.55$ & $91.70 \pm 13.01$ & 0.26 \\
\hline Insulin $(\mu \mathrm{IU} / \mathrm{ml})$ & $25.74 \pm 17.48$ & $26.51 \pm 18.56$ & $21.61 \pm 9.24$ & 0.50 \\
\hline HOMA-IR & $6.26 \pm 5.07$ & $6.58 \pm 5.41$ & $4.52 \pm 1.86$ & 0.30 \\
\hline $\operatorname{ESR}(\mathrm{mm} / \mathrm{h})$ & $16.59 \pm 8.9$ & $15.36 \pm 7.92$ & $19.67 \pm 11.52$ & 0.24 \\
\hline CRP (mg/dl) & $10.59 \pm 6.6$ & $10.02 \pm 6.57$ & $12.02 \pm 6.69$ & 0.36 \\
\hline IL6 (pg/ml) & $4.01 \pm 3.20$ & $3.76 \pm 2.72$ & $4.07 \pm 3.40$ & 0.23 \\
\hline $25(\mathrm{OH}) \mathrm{D}(\mathrm{ng} / \mathrm{ml})$ & $16.75 \pm 11.68$ & $16.58 \pm 7.20$ & $17.31 \pm 20.98$ & 0.85 \\
\hline AspAt (U/l) & $29.14 \pm 10.13$ & $30.17 \pm 10.74$ & $27.83 \pm 8.19$ & 0.24 \\
\hline AlAt (U/l) & $43.86 \pm 15.17$ & $44.70 \pm 16.23$ & $41.36 \pm 11.77$ & 0.29 \\
\hline Total cholesterol (mg/dl) & $180.59 \pm 41.61$ & $180.51 \pm 39.06$ & $180.83 \pm 51.00$ & 0.98 \\
\hline HDL-cholesterol (mg/dl) & $42.09 \pm 10.42$ & $40.13 \pm 9.44$ & $48.49 \pm 11.28$ & 0.01 \\
\hline LDL-cholesterol (mg/dl) & $112.55 \pm 36.26$ & $112.62 \pm 35.01$ & $112.33 \pm 41.71$ & 0.98 \\
\hline Triglycerides (mg/dl) & $132.63 \pm 58.65$ & $142.54 \pm 62.91$ & $100.42 \pm 22.02$ & 0.03 \\
\hline Folic acid (ng/ml) & $7.59 \pm 3.54$ & $8.11 \pm 3.72$ & $5.93 \pm 2.31$ & 0.06 \\
\hline $\mathrm{B}_{12}(\mathrm{pg} / \mathrm{mL})$ & $319.04 \pm 111.70$ & $321.21 \pm 116.19$ & $312.00 \pm 100.06$ & 0.81 \\
\hline Systolic b. p. (mmHg) & $139.88 \pm 20.87$ & $136.11 \pm 20.96$ & $140.50 \pm 22.72$ & 0.22 \\
\hline Diastolic b. p. (mmHg) & $79.28 \pm 9.53$ & $77.03 \pm 9.44$ & $75.50 \pm 9.21$ & 0.74 \\
\hline
\end{tabular}


Table 2 Fatty acid composition in serum of patients $(n=51)$ and differences between these parameters in patients with high $(>$ Q3) and low $(\leq \mathrm{Q} 3)$ PUFA levels

\begin{tabular}{|c|c|c|c|c|}
\hline Fatty acids (\%) & Total $(n=51)$ & $\begin{array}{l}\text { PUFA } \leq 32.84 \% \\
\text { (Q3) }(n=39)\end{array}$ & $\begin{array}{l}\text { PUFA }>32.84 \% \\
(\mathrm{Q} 3)(n=12)\end{array}$ & $p$ value \\
\hline \multicolumn{5}{|l|}{ SFA } \\
\hline C8:0 (caprylic) & $1.32 \pm 0.59$ & $1.31 \pm 0.62$ & $1.36 \pm 0.52$ & 0.79 \\
\hline C10:0 (capric) & $1.62 \pm 0.55$ & $1.64 \pm 0.60$ & $1.58 \pm 0.35$ & 0.76 \\
\hline C12:0 (lauric) & $0.90 \pm 0.31$ & $0.91 \pm 0.35$ & $0.87 \pm 0.17$ & 0.70 \\
\hline C13:0 (tridecylic) & $0.15 \pm 0.20$ & $0.18 \pm 0.22$ & $0.11 \pm 0.16$ & 0.62 \\
\hline C14:0 (myristic) & $0.80 \pm 0.27$ & $0.86 \pm 0.29$ & $0.63 \pm 0.11$ & 0.01 \\
\hline C15:0 (pentadecanoic) & $0.19 \pm 0.06$ & $0.19 \pm 0.06$ & $0.17 \pm 0.03$ & 0.25 \\
\hline C16:0 (palmitic) & $25.12 \pm 2.49$ & $25.87 \pm 2.26$ & $22.69 \pm 1.45$ & 0.00 \\
\hline C17:0 (margaric) & $0.24 \pm 0.08$ & $0.24 \pm 0.07$ & $0.25 \pm 0.11$ & 0.88 \\
\hline C18:0 (stearic) & $6.63 \pm 0.80$ & $6.69 \pm 0.85$ & $6.42 \pm 0.63$ & 0.32 \\
\hline C20:0 (arachidic) & $0.06 \pm 0.04$ & $0.06 \pm 0.04$ & $0.06 \pm 0.03$ & 0.96 \\
\hline C21:0 (heneicosylic) & $0.16 \pm 0.06$ & $0.16 \pm 0.05$ & $0.19 \pm 0.09$ & 0.07 \\
\hline C22:0 (behenic) & $0.04 \pm 0.01$ & $0.03 \pm 0.01$ & $0.05 \pm 0.00$ & 0.22 \\
\hline C23:0 (tricosylic) & $0.22 \pm 0.13$ & $0.24 \pm 0.13$ & $0.15 \pm 0.10$ & 0.06 \\
\hline C24:0 (lignoceric) & $0.06 \pm 0.02$ & $0.06 \pm 0.02$ & $0.07 \pm 0.02$ & 0.04 \\
\hline \multicolumn{5}{|l|}{ MUFA } \\
\hline C14:1 n-5 (myristoleic) & $0.05 \pm 0.03$ & $0.05 \pm 0.03$ & $0.04 \pm 0.02$ & 0.32 \\
\hline C16:1 n-7 (palmitoleic) & $3.14 \pm 0.72$ & $3.27 \pm 0.70$ & $2.72 \pm 0.60$ & 0.02 \\
\hline C17:1 n-10 (margarolein) & $0.23 \pm 0.09$ & $0.23 \pm 0.08$ & $0.22 \pm 0.10$ & 0.63 \\
\hline C18:1 trans n-9 (elaidic) & $0.17 \pm 0.12$ & $0.18 \pm 0.13$ & $0.14 \pm 0.08$ & 0.34 \\
\hline C18:1 cis n-9 (oleic) & $24.56 \pm 2.04$ & $25.08 \pm 1.93$ & $22.86 \pm 1.37$ & $\mathbf{0 . 0 0}$ \\
\hline cis-11 C20:1 n-9 (eicosenoic) & $0.18 \pm 0.07$ & $0.19 \pm 0.07$ & $0.17 \pm 0.03$ & 0.35 \\
\hline cis-13 C22:1 n-9 (erucic) & $0.08 \pm 0.07$ & $0.09 \pm 0.07$ & $0.08 \pm 0.08$ & 0.86 \\
\hline \multicolumn{5}{|l|}{ PUFA } \\
\hline C18:2 n-9 (linolelaidic) & $3.05 \pm 0.36$ & $3.08 \pm 0.35$ & $2.98 \pm 0.41$ & 0.40 \\
\hline C18:2 n-6 (LA; linoleic) & $20.82 \pm 2.65$ & $19.99 \pm 2.38$ & $23.52 \pm 1.46$ & 0.00 \\
\hline C18:3 n-6 (GLA; $\gamma$-linolenic) & $0.20 \pm 0.12$ & $0.19 \pm 0.10$ & $0.25 \pm 0.15$ & 0.09 \\
\hline C18:3 n-3 (ALA; $\alpha$-linolenic) & $0.54 \pm 0.17$ & $0.52 \pm 0.16$ & $0.61 \pm 0.19$ & 0.09 \\
\hline c9,t11-CLA (conjugated linoleic) & $0.10 \pm 0.04$ & $0.11 \pm 0.04$ & $0.09 \pm 0.03$ & 0.31 \\
\hline C20:2 n-6 (eicosadienoic) & $0.10 \pm 0.08$ & $0.10 \pm 0.09$ & $0.12 \pm 0.06$ & 0.42 \\
\hline C20:3 n-6 (dihomo- $\gamma$-linolenic) & $1.10 \pm 0.29$ & $1.07 \pm 0.28$ & $1.20 \pm 0.32$ & 0.20 \\
\hline C20:3 n-3 (eicosatrienoic) & $0.13 \pm 0.16$ & $0.13 \pm 0.18$ & $0.16 \pm 0.07$ & 0.62 \\
\hline C20:4 n-6 (AA; arachidonic) & $3.82 \pm 1.20$ & $3.36 \pm 0.69$ & $5.34 \pm 1.24$ & $\mathbf{0 . 0 0}$ \\
\hline C20:5 n-3 (EPA; eicosapentaenoic) & $0.37 \pm 0.19$ & $0.33 \pm 0.17$ & $0.50 \pm 0.19$ & 0.01 \\
\hline C22:2 n-6 (docosadienoic) & $0.29 \pm 0.17$ & $0.31 \pm 0.16$ & $0.24 \pm 0.18$ & 0.23 \\
\hline C22:6 n-3 (DHA; docosahexaenoic) & $0.77 \pm 0.36$ & $0.66 \pm 0.25$ & $1.13 \pm 0.44$ & $\mathbf{0 . 0 0}$ \\
\hline \multicolumn{5}{|l|}{ Total content } \\
\hline$\sum \mathrm{SFA}$ & $37.59 \pm 3.12$ & $38.56 \pm 2.81$ & $34.44 \pm 1.61$ & $\mathbf{0 . 0 0}$ \\
\hline$\sum$ MUFA & $28.36 \pm 2.40$ & $29.03 \pm 2.20$ & $26.17 \pm 1.63$ & $\mathbf{0 . 0 0}$ \\
\hline$\sum$ PUFA & $31.23 \pm 3.77$ & $29.74 \pm 2.80$ & $36.09 \pm 1.98$ & $\mathbf{0 . 0 0}$ \\
\hline$\sum \mathrm{n}-3$ & $1.78 \pm 0.67$ & $1.60 \pm 0.56$ & $2.36 \pm 0.71$ & $\mathbf{0 . 0 0}$ \\
\hline$\sum \mathrm{n}-6$ & $25.92 \pm 3.56$ & $24.57 \pm 2.77$ & $30.31 \pm 1.91$ & 0.00 \\
\hline$n-6 / n-3$ & $16.21 \pm 5.18$ & $16.89 \pm 5.21$ & $14.01 \pm 4.63$ & 0.09 \\
\hline
\end{tabular}

$75.5 \%$ of discriminatory power, whereas DF2 explains $24.5 \%$ of discriminatory power (Table 3 ).

Analysis of canonical mean variables indicated that DF1 had the greatest impact on the distinction of serum samples obtained from patients with obesity and type II diabetes, whereas DF2 seemed to distinguish patients with obesity and dyslipidemia from obese patients, without coexisting diabetes or dyslipidemia. Graph analysis confirms the suggestion provided by the values of average canonic variables (Fig. 2). 
The calculated classification matrix indicated that average classification efficiency based on the calculated functions was $93.5 \%$. For individual groups, these coefficients were as follows: $100 \%$ for obese patients with diabetes, $96 \%$ for obese patients without coexisting diabetes or dyslipidemia, and $85 \%$ for obese patients with dyslipidemia. Thus, the applied LDA allowed to observe significant differences among all three distinguished groups of patients which indicated that the analysis of fatty acid profile in serum samples allowed for the distinction of the origin of the sample with high probability. The fatty acid profile of serum samples elaborated with various chemometric methods can be used to some extent to differentiate health status of obese patients.

A comparison of serum fatty acid profiles in patients at baseline and at a follow-up visit $(n=23), 1$ year after laparoscopic sleeve gastrectomy (LSG), is presented in Table 4. The mean BMI value of the subjects at 12 months post-surgery was $31.73 \pm 4.76 \mathrm{~kg} / \mathrm{m}^{2}$. Mean weight loss was $34.8 \mathrm{~kg}(-46.6 \%)$ during the first year after surgery. The observed weight reduction had an effect on the fatty acid profile. Compared to baseline, patients after bariatric surgery had significantly lower percentage shares of such SFA as C8:0 (caprylic), C10:0 (capric), C12:0 (lauric), C14:0 (myristic), C16:0 (palmitic), and C23:0 (tricosanic); and of MUFA such as C14:1 (myristoleic), C16:1 (palmitoleic), and C18:1 trans n-9 (elaidic); as well as a lower total percentage of serum SFA. Significant weight reduction achieved as a result of bariatric surgery also resulted in a statistically significantly lower total percentage of MUFA. Patients after the bariatric surgery were characterized by a significantly higher total percentage of PUFA. Specifically, they had higher percentages of linoleic, arachidonic, and DHA (docosahexaenoic) compared to patients at baseline (Table 4).

\section{Discussion}

Our study showed that in the patients with clinically severe obesity before bariatric surgery, palmitic acid (C16:0) and oleic acid (C18:1 cis n-9) predominated among total plasma saturated fatty acids, comprising $\approx 25 \%$, followed by linoleic acid (LA, C18:2 n-6, $\approx 21 \%$ ) and stearic acid (C18:0, $\approx$ $7 \%$ ). Our observations were similar to those of other authors. Mayneris-Perxachs et al. [35] found similar values in stearic acid $(\approx 7 \%)$ and oleic acid $(\approx 26 \%)$, but found lower values in palmitic acid $(\approx 22 \%)$, and higher values in linoleic acid $(\approx 28 \%)$ in a Mediterranean population with metabolic syndrome. In particular, we examined the concentration of circulating PUFA, which have two or more double bonds in the hydrocarbon chain, because the hallmarks for most metabolic pathologies are an increased content of SFA and a lower content of PUFA. Obese individuals in the highest quartile (Q3 quartile) of serum PUFA (\% PUFA > 32.84\%) had a significantly lower percentage of SFA, especially C14:0 (myristic), C16:0 (palmitic), and C24:0 (lignoceric), and lower percentages of selected MUFA; i.e., C16:1 n-7 (palmitoleic) and C18:1 cis n-9 (oleic). Similarly, previous studies showed that people who followed a diet rich in PUFA had lower serum content of palmitic [25, 36], palmitoleic, and oleic [25] acids than controls. This indicates that the measurement of fatty acid composition in serum is a highly objective method which can be comparable with intake of
Fig. 1 Heatmap of fatty acids percentage share differing significantly among three groups of obese patients (patients with obesity, with obesity and type II diabetes, with obesity and dyslipidemia)

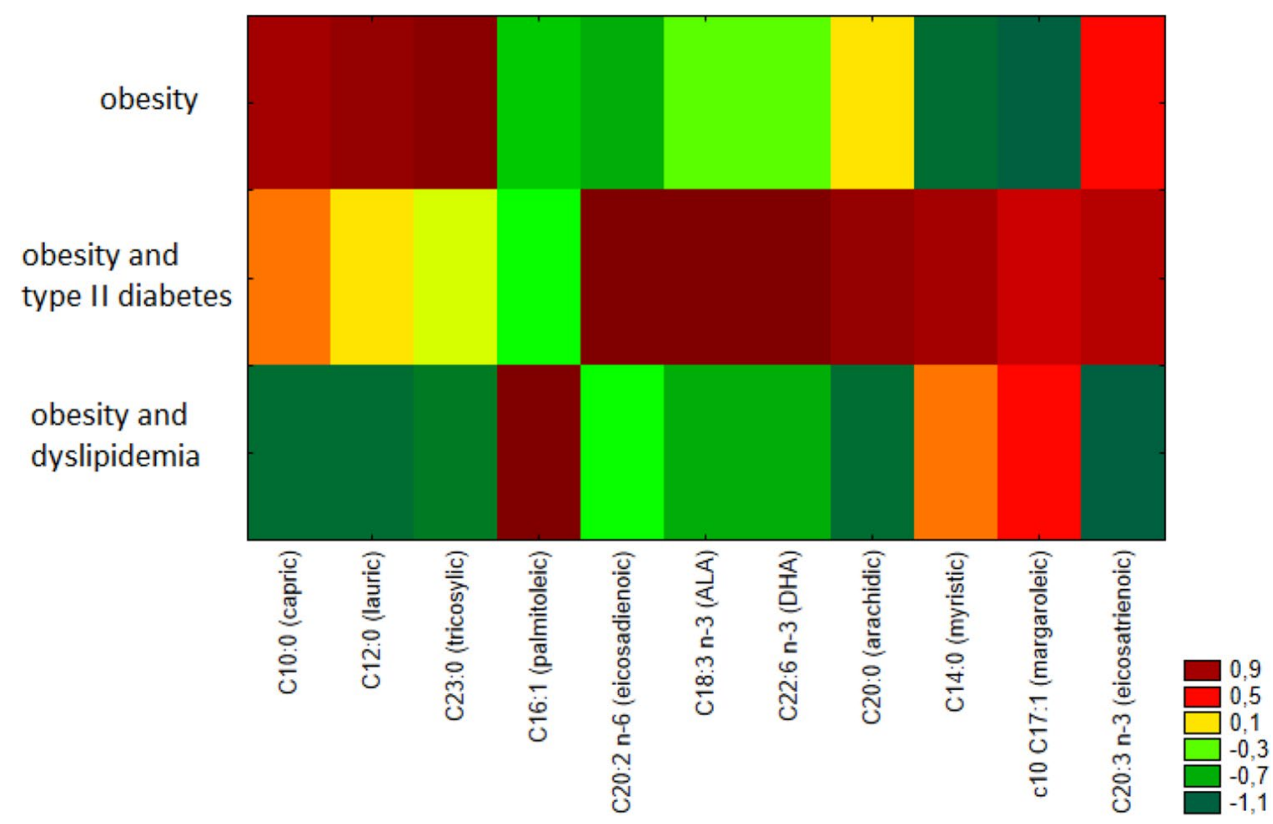


Table 3 Coefficients and average value of canonical variables included in the final model

\begin{tabular}{lll}
\hline Coefficients of canonical variables & & \\
\hline Variable & DF1 & DF2 \\
(discriminatory power) & $(75.5 \%)$ & $(24.5 \%)$ \\
\hline C20:2 n-6 (eicosadienoic) & -0.613577 & 0.126347 \\
C14:0 (myristic) & -0.667717 & 0.420873 \\
C20:0 (arachidic) & -0.880123 & -0.515471 \\
C22:6 n-3 (DHA; docosahexaenoic) & -0.568455 & -0.129122 \\
C12:0 (lauric) & -0.141228 & -0.461123 \\
c9,t11-CLA (conjugated linoleic) & 1.214006 & 0.029185 \\
C21:0 (heneicosylic) & -0.622736 & 0.089075 \\
C15:0 (pentadecanoic) & -0.645252 & -0.211645 \\
C23:0 (tricosylic) & 0.314426 & -0.647146 \\
C18:2 n-6 (LA; linoleic) & -0.662071 & 0.161652 \\
C20:4 n-6 (AA; arachidonic) & 0.955566 & -0.725548 \\
C24:0 (lignoceric) & -0.725548 & 0.268595 \\
C18:1 trans n-9 (elaidic) & 0.408686 & 0.060113 \\
Average value of canonical variables & & \\
$\quad$ Dyslipidemia & 0.75753 & 1.467863 \\
Diabetes & -4.34991 & 0.099946 \\
Obesity & 0.60191 & -0.728959 \\
\hline
\end{tabular}

dietary fat. It should also be emphasized that a low content of C16:0 (palmitic acid) is critical because a relationship has been demonstrated between an elevated level thereof and the development of type II diabetes, cardiovascular disease, and cancer [37]. Palmitic acid stimulates proinflammatory mechanisms through both Toll-like receptor
4 (TLR4)-mediated inflammatory signaling [38] and reactive oxygen species (ROS) in a TLR-independent manner [39]; induces central leptin resistance; and impairs hepatic glucose and lipid metabolism [40]. The lower level of palmitoleic acid observed here was probably related to decreased palmitic acid intake, resulting in decreased endogenous desaturation of palmitic acid to palmitoleic acid. Moreover, our findings provide evidence for a positive correlation between serum C-reactive protein (CRP) concentrations and palmitic acid (C16:0) and IL-6 levels. This is in line with the fact that they are two functionally linked biomarkers and that hepatic synthesis of CRP is regulated by IL-6 [41, 42]. The functional framework between IL-6 and CRP [42] may be strongly influenced by the increased production of IL-6 by human adipose tissue in cases of obesity. Moreover, CRP has been shown to be expressed in adipocytes in response to pro-inflammatory mediators, representing yet another link between obesity and chronic inflammation [43]. On the other hand, patients with higher serum total PUFFA ( $>$ Q3 quartile) had a higher percentage of linoleic acid (LA), arachidonic acid (AA), EPA (eicosapentaenoic acid), and DHA (docosahexaenoic acid) compared to patients with lower PUFA levels (\% PUFA $\leq$ Q3). The higher serum total n-3 fatty acid content in this group was accompanied by a higher proportion of total n- 6 fatty acid in serum. Similar results were obtained by Summers et al., where individuals on a diet rich in PUFA had increased LA (linoleic acid) concentrations [25]. Several lines of evidence have indicated that, as with the n- 3 fatty acids, the n- 6 reduce risk for coronary heart disease (CHD) [44, 45]. In our study, the main n-6 PUFA, LA, was associated with lower CRP.
Fig. 2 Scatter plot of canonical values for functions DF1 and DF2

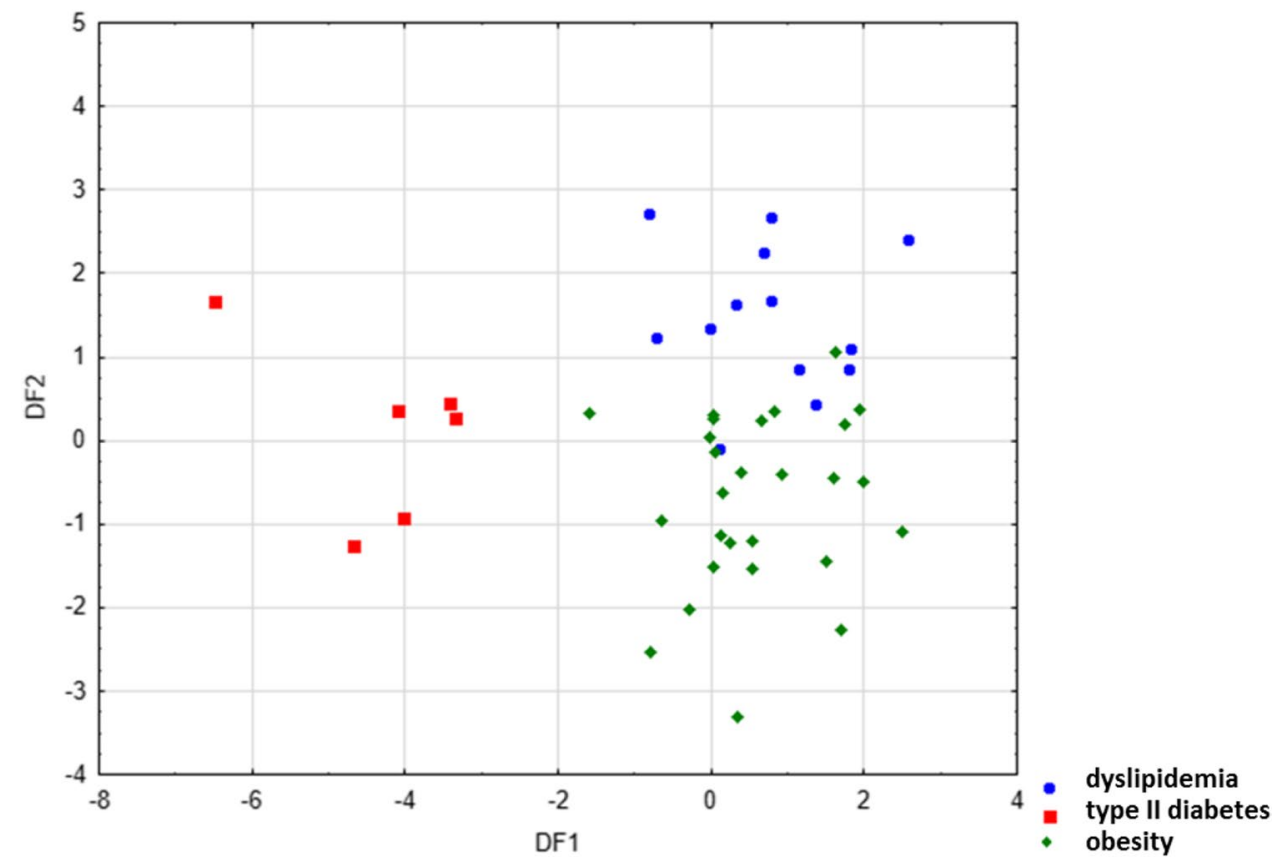


Table 4 Changes in fatty acid composition in serum after weight loss (WL) achieved by laparoscopic sleeve gastrectomy (LSG)

\begin{tabular}{|c|c|c|c|c|}
\hline Fatty acids (\%) & Baseline & After WL & Change & $p$ value \\
\hline \multicolumn{5}{|l|}{ SFA } \\
\hline C6:0 (caproic) & n.d & n.d & - & - \\
\hline C8:0 (caprylic) & $1.47 \pm 0.57$ & $1.13 \pm 0.80$ & -0.34 & 0.04 \\
\hline C10:0 (capric) & $1.67 \pm 0.48$ & $1.21 \pm 0.69$ & -0.46 & 0.01 \\
\hline C11:0 (undecylic) & n.d & n.d & - & - \\
\hline C12:0 (lauric) & $0.92 \pm 0.26$ & $0.64 \pm 0.33$ & -0.28 & 0.00 \\
\hline C13:0 (tridecylic) & $0.13 \pm 0.19$ & $0.12 \pm 0.13$ & -0.01 & 0.82 \\
\hline C14:0 (myristic) & $0.80 \pm 0.34$ & $0.63 \pm 0.32$ & -0.18 & $\mathbf{0 . 0 3}$ \\
\hline C15:0 (pentadecanoic) & $0.18 \pm 0.05$ & $0.19 \pm 0.06$ & 0.00 & 0.69 \\
\hline C16:0 (palmitic) & $25.81 \pm 2.74$ & $23.68 \pm 2.41$ & -2.13 & 0.00 \\
\hline C17:0 (margaric) & $0.25 \pm 0.09$ & $0.25 \pm 0.07$ & 0.00 & 0.81 \\
\hline C18:0 (stearic) & $6.62 \pm 0.84$ & $6.51 \pm 0.61$ & -0.11 & 0.47 \\
\hline C20:0 (arachidic) & $0.05 \pm 0.04$ & $0.06 \pm 0.09$ & 0.02 & 0.47 \\
\hline C21:0 (heneicosylic) & $0.17 \pm 0.07$ & $0.15 \pm 0.04$ & -0.02 & 0.27 \\
\hline C22:0 (behenic) & n.d & n.d & - & - \\
\hline C23:0 (tricosylic) & $0.24 \pm 0.10$ & $0.14 \pm 0.09$ & -0.10 & 0.00 \\
\hline C24:0 (lignoceric) & $0.05 \pm 0.01$ & $0.04 \pm 0.01$ & -0.01 & 0.30 \\
\hline \multicolumn{5}{|l|}{ MUFA } \\
\hline C14:1 n-5 (myristoleic) & $0.04 \pm 0.02$ & $0.03 \pm 0.02$ & -0.02 & 0.00 \\
\hline C15:1 n-10 (pentadecenoic) & n.d & n.d & - & - \\
\hline C16:1 n-7 (palmitoleic) & $3.16 \pm 0.74$ & $2.24 \pm 0.80$ & -0.91 & 0.00 \\
\hline C17:1 n-10 (margarolein) & $0.24 \pm 0.10$ & $0.26 \pm 0.15$ & 0.02 & 0.58 \\
\hline C18:1 trans n-9 (elaidic) & $0.20 \pm 0.15$ & $0.10 \pm 0.04$ & -0.10 & $\mathbf{0 . 0 3}$ \\
\hline C18:1 cis n-9 (oleic) & $24.52 \pm 1.97$ & $24.14 \pm 2.60$ & -0.38 & 0.39 \\
\hline cis-11 C20:1 n-9 (eicosenoic) & $0.18 \pm 0.05$ & $0.22 \pm 0.09$ & 0.04 & 0.01 \\
\hline cis-13 C22:1 n-9 (erucic) & $0.02 \pm 0.00$ & n.d & - & - \\
\hline C24:1 n-9 (nervonic) & n.d & n.d & - & - \\
\hline \multicolumn{5}{|l|}{ PUFA } \\
\hline C18:2 n-9 (linolelaidic) & $3.07 \pm 0.32$ & $2.93 \pm 0.37$ & -0.14 & 0.11 \\
\hline C18:2 n-6 (LA; linoleic) & $20.63 \pm 3.32$ & $24.37 \pm 4.26$ & 3.74 & 0.00 \\
\hline C18:3 n-6 (GLA; $\gamma$-linolenic) & $0.17 \pm 0.13$ & $0.16 \pm 0.09$ & -0.01 & 0.61 \\
\hline C18:3 n-3 (ALA; $\alpha$-linolenic) & $0.53 \pm 0.19$ & $0.51 \pm 0.33$ & -0.02 & 0.78 \\
\hline c9,t11-CLA (conjugated linoleic) & $0.09 \pm 0.03$ & $0.10 \pm 0.06$ & 0.01 & 0.54 \\
\hline C20:2 n-6 (eicosadienoic) & $0.09 \pm 0.05$ & $0.10 \pm 0.06$ & 0.01 & 0.41 \\
\hline C20:3 n-6 (dihomo- $\gamma$-linolenic) & $0.96 \pm 0.24$ & $0.95 \pm 0.24$ & -0.01 & 0.79 \\
\hline C20:3 n-3 (eicosatrienoic) & $0.25 \pm 0.35$ & $0.16 \pm 0.14$ & -0.08 & 0.62 \\
\hline C20:4 n-6 (AA; arachidonic) & $3.47 \pm 1.14$ & $4.68 \pm 1.41$ & 1.21 & $\mathbf{0 . 0 0}$ \\
\hline C20:5 n-3 (EPA; eicosapentaenoic) & $0.34 \pm 0.20$ & $0.34 \pm 0.15$ & 0.01 & 0.82 \\
\hline C22:2 n-6 (docosadienoic acid) & $0.34 \pm 0.18$ & $0.22 \pm 0.17$ & -0.12 & 0.11 \\
\hline C22:6 n-3 (DHA; docosahexaenoic) & $0.71 \pm 0.34$ & $0.90 \pm 0.41$ & 0.19 & 0.00 \\
\hline \multicolumn{5}{|l|}{ Total content } \\
\hline$\sum$ SFA & $38.20 \pm 3.11$ & $34.61 \pm 2.93$ & -3.60 & 0.00 \\
\hline$\sum$ MUFA & $28.35 \pm 2.35$ & $26.97 \pm 3.09$ & -1.39 & 0.01 \\
\hline$\sum$ PUFA & $30.45 \pm 4.23$ & $35.27 \pm 5.57$ & 4.82 & 0.00 \\
\hline$\sum n-3$ & $1.69 \pm 0.68$ & $1.80 \pm 0.77$ & -0.11 & 0.39 \\
\hline$\sum \mathrm{n}-6$ & $25.19 \pm 4.20$ & $30.18 \pm 5.45$ & 4.99 & 0.00 \\
\hline$n-6 / n-3$ & $16.91 \pm 6.01$ & $18.87 \pm 6.27$ & -1.95 & 0.09 \\
\hline
\end{tabular}

Data expressed as mean $\pm \mathrm{SD} ; p$ values were considered significant when $p<0.05$ (in bold). Values at baseline were compared with post-surgery values using paired $t$-test 
When KIHD study's participants were divided into four groups based on their serum LA (linoleic acid) levels, the probability for an elevated CRP was 53\% lower in the highest quarter compared to the lowest one. Indeed, no evidence is available from randomized, controlled intervention studies to show that high intake of LA increases the concentration of inflammatory markers, including C-reactive protein, fibrinogen, plasminogen activator inhibitor type 1, cytokines, soluble vascular adhesion molecules, or tumor necrosis factor- $\alpha$ [46]. Moreover, in a study by Steffen et al., which involved 2848 adults from various ethnic groups, it was found that people with higher percentages of LA (linoleic acid) had statistically lower concentrations of CRP. In addition, plasma LA levels appear especially important among obese individuals in reducing the likelihood of high levels of sICAM-1 [47]. Also, Fernandez-Real et al. showed that serum CRP levels in individuals with obesity was negatively correlated with the percentage of LA (linoleic acid) $(p=0.03)$ [24].

In this study, patients with higher total PUFA percent had higher HDL-cholesterol levels and lower triglyceride concentrations, even though they had higher BMI, and this is consistent with the previous findings of Virtanen et al. [45]. Similarly, Hlavaty et al. [48] showed that moderately obese women assigned to a low calorie diet including yogurt enriched with n-3 PUFA showed a significant increase in HDL-cholesterol concentration and a decrease in triglyceride levels after 21 days. It has been shown that fatty acid component of structured triacylglycerols influences its digestion and absorption; moreover, PUFA are regulators of the expression of genes encoding proteins involved in energy metabolism and reduce triglyceride levels in plasma [49-51]. In addition, in our study, we can exclude the influence of cholesteryl ester-transfer protein (CETP) polymorphism on presented results. However, the lack of association between CETP Taq1B-variant and total PUFFA level should be treated as preliminary, because of small group of patients with $\mathrm{B} 2 \mathrm{~B} 2$ genotype. In general, cholesteryl ester-transfer protein (CETP) transfers cholesteryl esters from HDL to apolipoprotein $\mathrm{B}$ containing lipoproteins in exchange for triglycerides. Previous studies showed that the B2 allele in the CETP gene was associated with decreased CETP activity and increased HDL-C-cholesterol [52].

The serum fatty acid profile has previously been studied in patients with type II diabetes [53-56]. Some studies suggest that SFA can be associated with diabetes risk. In the present study, obese patients with type II diabetes were characterized by higher percentages of the following SFA: C14:0 (myristic), C20:0 (arachidic), and C21:0 (heneicosylic). However, we are not in accord with regard to the differences seen previously in the other SFA; e.g., C16:0 (palmitic) $[53,55,56]$ and C18:0 (stearic) $[55,56]$, between patients with and without type II diabetes. Similar to our data, a study conducted in England by Patel et al. [53] found increases in the percentages of myristic acid (14:0) and $\alpha$-linolenic acid (ALA, 18:3n-3) in patients with type II diabetes. In contrast, we found also DHA and total n-3 fatty acids to be increased in the patients with obesity and diabetes. In a study carried out in Australia, Hodge et al. [55] found increases in most fatty acids in patients with type II diabetes, including EPA and DHA. Thus, serum SFA level may be an important underlying cause of various obesityassociated conditions. The occurrence of obesity is usually accompanied by lipid metabolism disorders. We analyzed the fatty acid profile in the serum of obese patients with and without dyslipidemia. We noticed that patients with lipid metabolism disorders had significantly lower percentages of some SFA in the serum, such as C10:0 (capric), C12:0 (lauric), and C20:0 (arachidic). Previous studies have shown an increased level of total MUFA as the effect of hyperlipidemia [57], which is in agreement with our results for higher percentage of palmitoleic acid (C16:1). Such interaction may have resulted from the hypolipidemic treatment implemented in these patients [34]. Coupled with various chemometric methods, linear discriminant analysis (LDA) may be served as method to differentiate health status of patients with obesity. LDA allowed to distinguish with high probability the origin of the serum sample obtained from three distinguished groups of patient: obese patients, obese patients with type II diabetes, and obese patients with dyslipidemia. Previously, LDA has been proposed as a useful tool in different disorders diagnosis [58-60]. Further studies are necessary in order to conclude a final association between the FA profile and the prevalence of any obesityrelated complications. Evaluating these differences may be crucial in the approach to the candidate for bariatric surgery.

In order to maintain a good state of health, it is important to keep the dietary ratio of n-6 acids to $n-3$ low. High ratio may contribute to the development of cardiovascular diseases, cancers, inflammation, and autoimmune diseases [61]. In the present study, the average ratio of $n-6 / n-3$ fatty acids was $16.21 \pm 5.18$ in obese patients. Gupta et al. observed a relationship between the high ratio of $n-6 / n-3$ fatty acids and the occurrence of dyslipidemia in the population of Delhi [62]. In this study, it was observed that obese patients with dyslipidemia were characterized by a higher ratio of $n-6 / n-3$ fatty acids than patients with diabetes type II. It must be said that diabetics more effectively control their diets, because they are instructed not to eat excessive and fatty meals. That this instruction was quite well respected can be seen from the lower ratio of $n-6 / n-3$.

The results of many studies confirm the improvement of lipid parameters after weight reduction, e.g., due to surgical gastrectomy [63-67]. We also noted that patients after 
the 12-month period following LSG had more favorable percentages of some fatty acids. The examined patients were characterized by a statistically significant lower total percentage of saturated fatty acids (SFA), as well as lower percentages of individual SFA, such as C8:0 (caprylic), C10:0 (capric), C12:0 (lauric), C14:0 (myristic), C16:0 (palmitic), and C23:0 (tricosanic). Walle et al. also noted a statistically significant reduction in the total concentration of saturated fatty acids, especially C16:0 (palmitic) acid, 1 year after bariatric surgery. Such changes induced by obesity surgery are especially beneficial because palmitic acid in adipose tissue is negatively associated with insulin sensitivity. Similar to the study conducted by Walle et al. [68], who examined 122 people after surgical gastrectomy, we likewise observed that patients after surgical gastrectomy had higher concentrations of C20:1 (eicosenic), AA (arachidonic), DHA (docosahexaenoic), and LA (linoleic) acids, and higher total PUFA concentrations, than patients before surgery. This observation in our patients after bariatric surgery is attributed to the higher amounts of LA, which is a precursor of arachidonic acid. In general, AA has been characterized as an inflammation inducer due to its conversion into proinflammatory prostaglandins and leukotrienes. However, AA metabolism is a rigidly regulated process [69], and moderate elevations in body's AA concentrations in serum may have little to no net effect on the induction of pathophysiological processes. Alternatively, AA is a potent bioactive mediator that also regulates physiological processes, such as the production of anti-inflammatory lipoxin A4 [70] and the inhibition of the transcription factor nuclear factor- $\mathrm{KB}$ [71], which is associated with production and release of a number of cytokines, including IL-6. Moreover, after weight loss achieved by laparoscopic sleeve gastrectomy, we recognize decrease in major monounsaturated trans-fatty acid, elaidic acid, which is a reliable biomarker of highly processed foods [72], and may induce weight gain [73]. Thus may be of importance in maintaining weight loss.

Our study has several strengths: it included both obese patients with hyperlipidemia and with diabetes type II and had a good follow-up rate. However, further study is warranted to confirm our observation in changes in serum fatty acid levels during the first year after bariatric surgery, which suggests differences in fatty acid metabolism, and may also have implications in dietary fatty acid intake recommendations for obese individuals after bariatric surgery.

Acknowledgements We would like to thank Marek Głowala from the Medical University of Warsaw for assistance in genotyping and fatty acid determination. We would like to thank all the participants who took part in the study and the staff at the Orlowski Hospital in Warsaw, Poland.

Funding This work was supported by funds from the Ministry of Education and Science in Poland (SKN/SP/496250/2021), by the Medical
University of Warsaw under Grants FW113/NM1/17, FW113/PM2/17, 14/F/MG/21, and carried out through CePT infrastructure financed by the European Union (the European Regional Development Fund within the Operational Programme "Innovative economy" for 2007-2013).

\section{Declarations}

Ethical Approval All procedures performed in studies involving human participants were in accordance with the ethical standards of the 1964 Helsinki declaration and its later amendments. The study protocol was approved by the Local Bioethics Committees at the Medical University of Warsaw (approval no. KB/127/2012 and KB/67/2017, and at the Center of Postgraduate Medical Education (approval no. 7/PB/2015).

Informed Consent Written, informed consent was obtained from all participants included in the study.

Conflict of Interest The authors declare no competing interests.

Open Access This article is licensed under a Creative Commons Attribution 4.0 International License, which permits use, sharing, adaptation, distribution and reproduction in any medium or format, as long as you give appropriate credit to the original author(s) and the source, provide a link to the Creative Commons licence, and indicate if changes were made. The images or other third party material in this article are included in the article's Creative Commons licence, unless indicated otherwise in a credit line to the material. If material is not included in the article's Creative Commons licence and your intended use is not permitted by statutory regulation or exceeds the permitted use, you will need to obtain permission directly from the copyright holder. To view a copy of this licence, visit http://creativecommons.org/licenses/by/4.0/.

\section{References}

1. Agha M, Agha R. The rising prevalence of obesity: part A: impact on public health. Int J Surg Oncol. 2017;2(7):e17.

2. Dinsa GD, Goryakin Y, Fumagalli E, Suhrcke M. Obesity and socioeconomic status in developing countries: a systematic review. Obes Rev. 2012;13(11):1067-79.

3. Arner E, Westermark PO, Spalding KL, Britton T, Rydén M, Frisén J, Bernard S, Arner P. Adipocyte turnover: relevance to human adipose tissue morphology. Diabetes. 2010;59(1):105-9.

4. Mattson MP, Allison DB, Fontana L, Harvie M, Longo VD, Malaisse WJ, Mosley M, Notterpek L, Ravussin E, Scheer FAJL, et al. Meal frequency and timing in health and disease. Proc Natl Acad Sci U S A. 2014;111(47):16647-53.

5. He J, Goodpaster BH, Kelley DE. Effects of weight loss and physical activity on muscle lipid content and droplet size. Obes Res. 2004;12(5):761-9.

6. Galgani J, Ravussin E. Energy metabolism, fuel selection and body weight regulation. Int J Obes (Lond). 2008;32 Suppl 7(Suppl 7):S109-119.

7. Pereira-Lancha LO, Coelho DF, de Campos-Ferraz PL, Lancha $\mathrm{AH}$ Jr. Body fat regulation: is it a result of a simple energy balance or a high fat intake? J Am Coll Nutr. 2010;29(4):343-51.

8. Boateng L, Ansong R, Owusu WB, Steiner-Asiedu M. Coconut oil and palm oil's role in nutrition, health and national development: a review. Ghana Med J. 2016;50(3):189-96.

9. Siri-Tarino PW, Sun Q, Hu FB, Krauss RM. Saturated fatty acids and risk of coronary heart disease: modulation by replacement nutrients. Curr Atheroscler Rep. 2010;12(6):384-90. 
10. DiNicolantonio JJ, Lucan SC, O'Keefe JH. The evidence for saturated fat and for sugar related to coronary heart disease. Prog Cardiovasc Dis. 2016;58(5):464-72.

11. Cuthbertson DJ, Steele T, Wilding JP, Halford JC, Harrold JA, Hamer M, Karpe F. What have human experimental overfeeding studies taught us about adipose tissue expansion and susceptibility to obesity and metabolic complications? Int J Obes (Lond). 2017;41(6):853-65.

12. Kaur N, Chugh V, Gupta AK. Essential fatty acids as functional components of foods- a review. J Food Sci Technol. 2014;51(10):2289-303.

13. Monroig Ó, Kabeya N. Desaturases and elongases involved in polyunsaturated fatty acid biosynthesis in aquatic invertebrates: a comprehensive review. Fish Sci. 2018;84(6):911-28.

14. Williams JA, Batten SE, Harris M, Rockett BD, Shaikh SR, Stillwell W, Wassall SR. Docosahexaenoic and eicosapentaenoic acids segregate differently between raft and nonraft domains. Biophys J. 2012;103(2):228-37.

15. Nowak $\mathbf{J} \mathbf{Z}$. Anti-inflammatory pro-resolving derivatives of omega-3 and omega- 6 polyunsaturated fatty acids. Postepy Hig Med Dosw (Online). 2010;64:115-32.

16. Watanabe S, Sakai N, Yasui Y, Kimura Y, Kobayashi T, Mizutani T, Okuyama $\mathrm{H}$. A high $\alpha$-linolenate diet suppresses antigeninduced immunoglobulin E response and anaphylactic shock in mice. J Nutr. 1994;124(9):1566-73.

17. Huang CY, Sheu WH, Chiang AN. Docosahexaenoic acid and eicosapentaenoic acid suppress adhesion molecule expression in human aortic endothelial cells via differential mechanisms. Mol Nutr Food Res. 2015;59(4):751-62.

18. Bucher HC, Hengstler P, Schindler C, Meier G. N-3 polyunsaturated fatty acids in coronary heart disease: a meta-analysis of randomized controlled trials. Am J Med. 2002;112(4):298-304.

19. Saravanan P, Davidson NC, Schmidt EB, Calder PC. Cardiovascular effects of marine omega-3 fatty acids. The Lancet. 2010;376(9740):540-50.

20. Lee JH, O'Keefe JH, Lavie CJ, Harris WS. Omega-3 fatty acids: cardiovascular benefits, sources and sustainability. Nat Rev Cardiol. 2009;6:753.

21. Kulig W, Cwiklik L, Jurkiewicz P, Rog T, Vattulainen I. Cholesterol oxidation products and their biological importance. Chem Phys Lipid. 2016;199:144-60.

22. Buckley JD, Howe PRC. Long-chain omega-3 polyunsaturated fatty acids may be beneficial for reducing obesity-a review. Nutrients. 2010;2(12):1212-30.

23. Pan DA, Hulbert AJ, Storlien LH. Dietary fats, membrane phospholipids and obesity. J Nutr. 1994;124(9):1555-65.

24. Fernández-Real J-M, Broch M, Vendrell J, Ricart W. Insulin resistance, inflammation, and serum fatty acid composition. Diabetes Care. 2003;26(5):1362.

25. Summers LKM, Fielding BA, Bradshaw HA, Ilic V, Beysen C, Clark ML, Moore NR, Frayn KN. Substituting dietary saturated fat with polyunsaturated fat changes abdominal fat distribution and improves insulin sensitivity. Diabetologia. 2002;45(3):369-77.

26. Mirmiran P, Esfandiar Z, Hosseini-Esfahani F. Genetic variations of cholesteryl ester transfer protein and diet interactions in relation to lipid profiles and coronary heart disease: a systematic review. Nutr Metab (Lond). 2017;14:77.

27. Sandhofer A, Tatarczyk T, Laimer M, Ritsch A, Kaser S, Paulweber B, Ebenbichler CF, Patsch JR. The Taq1B-variant in the cholesteryl ester-transfer protein gene and the risk of metabolic syndrome. Obesity (Silver Spring, Md). 2008;16(4):919-22.

28. Obesity: preventing and managing the global epidemic. Report of a WHO consultation. World Health Organization technical report series. 2000;894:i-xii, 1-253.
29. Third Report of the National Cholesterol Education Program (NCEP) Expert Panel on Detection, Evaluation, and Treatment of High Blood Cholesterol in Adults (Adult Treatment Panel III) final report. Circulation. 2002;106(25):3143-421.

30. Standards of medical care in diabetes--2010. Diabetes Care. 2010;33(Supp11):S11-61.

31. Sarafidis PA, Lasaridis AN, Nilsson PM, Pikilidou MI, Stafilas PC, Kanaki A, Kazakos K, Yovos J, Bakris GL. Validity and reproducibility of HOMA-IR, 1/HOMA-IR, QUICKI and McAuley's indices in patients with hypertension and type II diabetes. J Hum Hypertens. 2007;21(9):709-16.

32. Bondia-Pons I, Moltó-Puigmartí C, Castellote AI, LópezSabater MC. Determination of conjugated linoleic acid in human plasma by fast gas chromatography. J Chromatogr A. 2007;1157(1-2):422-9.

33. Mohrschladt MF, van der Sman-de BF, Hofman MK, van der Krabben M, Westendorp RG, Smelt AH. TaqIB polymorphism in CETP gene: the influence on incidence of cardiovascular disease in statin-treated patients with familial hypercholesterolemia. Eur J Hum Genet. 2005;13(7):877-82.

34. Sahebkar A, Simental-Mendía LE, Pedone C, Ferretti G, Nachtigal P, Bo S, Derosa G, Maffioli P, Watts GF. Statin therapy and plasma free fatty acids: a systematic review and meta-analysis of controlled clinical trials. Br J Clin Pharmacol. 2016;81(5):807-18.

35. Mayneris-Perxachs J, Guerendiain M, Castellote AI, Estruch R, Covas MI, Fitó M, Salas-Salvadó J, Martínez-González MA, Aros F, Lamuela-Raventós RM, et al. Plasma fatty acid composition, estimated desaturase activities, and their relation with the metabolic syndrome in a population at high risk of cardiovascular disease. Clinical nutrition (Edinburgh, Scotland). 2014;33(1):90-7.

36. Hodson L, Skeaff CM, Chisholm WA. The effect of replacing dietary saturated fat with polyunsaturated or monounsaturated fat on plasma lipids in free-living young adults. Eur J Clin Nutr. 2001;55:908.

37. Mancini A, Imperlini E, Nigro E, Montagnese C, Daniele A, Orrù S, Buono P: Biological and nutritional properties of palm oil and palmitic acid: effects on health. Molecules. 2015;20(9):17339-61.

38. Ajuwon KM, Spurlock ME. Palmitate activates the NF-kappaB transcription factor and induces IL- 6 and TNFalpha expression in 3T3-L1 adipocytes. J Nutr. 2005;135(8):1841-6.

39. Wen H, Gris D, Lei Y, Jha S, Zhang L, Huang MT, Brickey WJ, Ting JP. Fatty acid-induced NLRP3-ASC inflammasome activation interferes with insulin signaling. Nat Immunol. 2011;12(5):408-15.

40. Cheng L, Yu Y, Szabo A, Wu Y, Wang H, Camer D, Huang XF. Palmitic acid induces central leptin resistance and impairs hepatic glucose and lipid metabolism in male mice. J Nutr Biochem. 2015;26(5):541-8.

41. Bastard J-P, Maachi M, Lagathu C, Kim MJ, Caron M, Vidal H, Capeau J, Feve B. Recent advances in the relationship between obesity, inflammation, and insulin resistance. Eur Cytokine Netw. 2006; 17:4-12.

42. Yudkin JS, Kumari M, Humphries SE, Mohamed-Ali V. Inflammation, obesity, stress and coronary heart disease: is interleukin-6 the link? Atherosclerosis. 2000;148(2):209-14.

43. Calabro P, Chang DW, Willerson JT, Yeh ET. Release of C-reactive protein in response to inflammatory cytokines by human adipocytes: linking obesity to vascular inflammation. J Am Coll Cardiol. 2005;46(6):1112-3.

44. Harris WS, Mozaffarian D, Rimm E, Kris-Etherton P, Rudel LL, Appel LJ, Engler MM, Engler MB, Sacks F. Omega-6 fatty acids and risk for cardiovascular disease: a science advisory from the American Heart Association Nutrition Subcommittee of the Council on Nutrition, Physical Activity, and Metabolism; Council on Cardiovascular Nursing; and Council on Epidemiology and Prevention. Circulation. 2009;119(6):902-7. 
45. Virtanen JK, Mursu J, Voutilainen S, Tuomainen T-P. The associations of serum $n-6$ polyunsaturated fatty acids with serum C-reactive protein in men: the Kuopio Ischaemic Heart Disease Risk Factor Study. Eur J Clin Nutr. 2018;72(3):342-8.

46. Su H, Liu R, Chang M, Huang J, Wang X. Dietary linoleic acid intake and blood inflammatory markers: a systematic review and meta-analysis of randomized controlled trials. Food Funct. 2017;8(9):3091-103.

47. Steffen BT, Steffen LM, Tracy R, Siscovick D, Hanson NQ, Nettleton J, Tsai MY. Obesity modifies the association between plasma phospholipid polyunsaturated fatty acids and markers of inflammation: the Multi-Ethnic Study of Atherosclerosis. Int J Obes (Lond). 2012;36(6):797-804.

48. Hlavatý P, Kunešová M, Gojová M, Tvrzická E, Vecka M, Roubal P, Hill M, Hlavatá K, Kalousková P, Hainer V, et al. Change in fatty acid composition of serum lipids in obese females after short-term weight-reducing regimen with the addition of n-3 long chain polyunsaturated fatty acids in comparison to controls. Physiol Res. 2008;57(Suppl 1):S57-s65.

49. Clarke SD, Gasperikova D, Nelson C, Lapillonne A, Heird WC. Fatty acid regulation of gene expression: a genomic explanation for the benefits of the Mediterranean diet. Ann N Y Acad Sci. 2002;967:283-98.

50. $\mathrm{Mu} \mathrm{H}$, Porsgaard T. The metabolism of structured triacylglycerols. Prog Lipid Res. 2005;44(6):430-48.

51. Lopez-Alvarenga JC, Ebbesson SO, Ebbesson LO, Tejero ME, Voruganti VS, Comuzzie AG. Polyunsaturated fatty acids effect on serum triglycerides concentration in the presence of metabolic syndrome components. The Alaska-Siberia Project. Metabolism. 2010;59(1):86-92.

52. Thompson A, Di Angelantonio E, Sarwar N, Erqou S, Saleheen D, Dullaart RP, Keavney B, Ye Z, Danesh J. Association of cholesteryl ester transfer protein genotypes with CETP mass and activity, lipid levels, and coronary risk. JAMA. 2008;299(23):2777-88.

53. Patel PS, Sharp SJ, Jansen E, Luben RN, Khaw K-T, Wareham NJ, Forouhi NG. Fatty acids measured in plasma and erythrocytemembrane phospholipids and derived by food-frequency questionnaire and the risk of new-onset type 2 diabetes: a pilot study in the European Prospective Investigation into Cancer and Nutrition (EPIC)-Norfolk cohort. Am J Clin Nutr. 2010;92(5):1214-22.

54. Perassolo MS, Almeida JC, Prá RL, Mello VD, Maia AL, Moulin CC, Camargo JL, Zelmanovitz T, Azevedo MJ, Gross JL. Fatty acid composition of serum lipid fractions in type 2 diabetic patients with microalbuminuria. Diabetes Care. 2003;26(3):613.

55. Hodge AM, English DR, O'Dea K, Sinclair AJ, Makrides M, Gibson RA, Giles GG. Plasma phospholipid and dietary fatty acids as predictors of type 2 diabetes: interpreting the role of linoleic acid. Am J Clin Nutr. 2007;86(1):189-97.

56. Wang LFA, Zheng ZJ, Pankow JS, Exkfeldt JH, Aric Study Investigators. Plasma fatty acid composition and incidence of diabetes in middle-aged adults: the Atherosclerosis Risk in Communities (ARIC) Study. Am J Clin Nutr. 2003;78(1):91-8.

57. Bohov P, Baláz V, Seböková E, Klimes I. The effect of hyperlipidemia on serum fatty acid composition in type 2 diabetics. Ann N Y Acad Sci. 1997;827:561-7.

58. Ricciardi C, Valente AS, Edmund K, Cantoni V, Green R, Fiorillo A, Picone I, Santini S, Cesarelli M. Linear discriminant analysis and principal component analysis to predict coronary artery disease. Health Informatics J. 2020;26(3):2181-92.

59. Krafft C, Thümmler K, Sobottka SB, Schackert G, Salzer R. Classification of malignant gliomas by infrared spectroscopy and linear discriminant analysis. Biopolymers. 2006;82(4):301-5.
60. Shayan Z, Mohammad Gholi Mezerji N, Shayan L, Naseri P. Prediction of depression in cancer patients with different classification criteria, linear discriminant analysis versus logistic regression. Glob J Health Sci. 2015;8(7):41-6.

61. Simopoulos AP. The importance of the ratio of omega-6/omega-3 essential fatty acids. Biomed Pharmacother. 2002;56(8):365-79.

62. Gupta R, Lakshmy R, Abraham RA, Reddy KS, Jeemon P, Prabhakaran D. Serum omega-6/omega-3 ratio and risk markers for cardiovascular disease in an industrial population of Delhi. Food Nutr Sci. 2013;4(9A):94-7.

63. Sjöström L, Lindroos A-K, Peltonen M, Torgerson J, Bouchard C, Carlsson B, Dahlgren S, Larsson B, Narbro K, Sjöström CD, et al. Lifestyle, diabetes, and cardiovascular risk factors 10 years after bariatric surgery. N Engl J Med. 2004;351(26):2683-93.

64. Holzwarth R, Huber D, Majkrzak A, Tareen B. Outcome of gastric bypass patients. Obes Surg. 2002;12(2):261-4.

65. Sjöström L, Narbro K, Sjöström CD, Karason K, Larsson B, Wedel H, Lystig T, Sullivan M, Bouchard C, Carlsson B, et al. Effects of bariatric surgery on mortality in swedish obese subjects. N Engl J Med. 2007;357(8):741-52.

66. Våge V, Sande VA, Mellgren G, Laukeland C, Behme J, Andersen JR. Changes in obesity-related diseases and biochemical variables after laparoscopic sleeve gastrectomy: a two-year follow-up study. BMC Surg. 2014;14:8-8.

67. Lee W-J, Huang M-T, Wang W, Lin C-M, Chen T-C, Lai IR. Effects of Obesity surgery on the metabolic syndrome. Arch Surg. 2004;139(10):1088-92.

68. Walle P, Takkunen M, Männistö V, Vaittinen M, Käkelä P, Ågren J, Schwab U, Lindström J, Tuomilehto J, Uusitupa M, et al. Alterations in fatty acid metabolism in response to obesity surgery combined with dietary counseling. Nutr Diabetes. 2017;7(9):e285-e285.

69. Leslie CC. Regulation of arachidonic acid availability for eicosanoid production. Biochem Cell Biol. 2004;82(1):1-17.

70. Liu H, Huang W, Chen L, Xu Q, Ye D, Zhang D. Glucocorticoid exposure induces preeclampsia via dampeninglipoxin $\mathrm{A}(4)$, an endogenous anti-inflammatory and proresolving mediator. Front Pharmacol. 2020;11:1131.

71. Alaoui-El-Azher $\mathrm{M}, \mathrm{Wu} \mathrm{Y}$, Havet $\mathrm{N}$, Israël A, Lilienbaum A, Touqui L. Arachidonic acid differentially affects basal and lipopolysaccharide-induced SPLA(2)-IIA expression in alveolar macrophages through NF-kappaB and PPAR-gamma-dependent pathways. Mol Pharmacol. 2002;61(4):786-94.

72. Chajès V, Biessy C, Byrnes G, Deharveng G, Saadatian-Elahi M, Jenab M, Peeters PH, Ocké M, Bueno-de-Mesquita HB, Johansson I, et al. Ecological-level associations between highly processed food intakes and plasma phospholipid elaidic acid concentrations: results from a cross-sectional study within the European prospective investigation into cancer and nutrition (EPIC). Nutr Cancer. 2011;63(8):1235-50.

73. Chajès V, Biessy C, Ferrari P, Romieu I, Freisling H, Huybrechts I, Scalbert A, Bueno de Mesquita B, Romaguera D, Gunter MJ, et al. Plasma elaidic acid level as biomarker of industrial trans fatty acids and risk of weight change: report from the EPIC study. PloS One. 2015;10(2):e0118206.

Publisher's Note Springer Nature remains neutral with regard to jurisdictional claims in published maps and institutional affiliations. 